\title{
Rapid biotic molecular transformation of fulvic acids in a karst aquifer
}

\author{
Florian Einsiedl ${ }^{\mathrm{a}, *}$, Norbert Hertkorn ${ }^{\mathrm{b}}$, Manfred Wolf ${ }^{\mathrm{a}}$, Moritz Frommberger ${ }^{\mathrm{b}}$, \\ Philippe Schmitt-Kopplin ${ }^{\mathrm{b}}$, Boris P. Koch ${ }^{\mathrm{c}}$ \\ a Institute of Groundwater Ecology, GSF-National Research Center for Environment and Health, Ingolstaedter Landstrasse 1, \\ D-85764 Neuherberg, Germany \\ ${ }^{\mathrm{b}}$ Institute of Ecological Chemistry, GSF-National Research Center for Environment and Health, Ingolstaedter Landstrasse 1, \\ D-85764 Neuherberg, Germany \\ ${ }^{\mathrm{c}}$ Alfred Wegener Institute for Polar and Marine Research, Ecological Chemistry, Am Handelshafen 12, D-27570 Bremerhaven, Germany
}

Received 26 June 2007; accepted in revised form 12 September 2007; available onilne 1 October 2007

\begin{abstract}
The study of molecular transformation processes of dissolved organic carbon (DOC) in the environment significantly contributes to a better understanding of the global biogeochemical organic matter cycle. In an oxic karst groundwater system, in which the most powerful abiotic DOC degradative reactions, photodegradation and metal-mediated redox chemistry, are at best marginal contributors, a near complete turnover of fulvic acids (FAs) has been observed within decades ( $\sim 60$ years). Depletion of oxygen for a very extensive range of aliphatic and aromatic carbon chemical environments has been confirmed as well as the formation of novel classes of compounds, suggesting a major contribution from biotic processes. From these results we infer that FAs must be perceived as a rather active participant in the global carbon cycle. Molecular-level alterations of such magnitude and rapidity on such short-time scales ought to be considered as widespread in the processing of "refractory" DOC in the environment.
\end{abstract}

(C) 2007 Elsevier Ltd. All rights reserved.

\section{INTRODUCTION}

Humic acids (HAs) and fulvic acids (FAs) typically account for $20-60 \%$ of the ubiquitous dissolved organic carbon (DOC) pool in aquatic environments (Abbt-Braun and Frimmel, 2002). Microbial utilization and transformation of humic substances (HS) as confirmed by laboratory studies and observed in surface waters and marine environments (Bianchi et al., 1996; Krumholz et al., 1997; Lovley et al., 1999; Ogawa et al., 1999; Hertkorn et al., 2002a; Hansell et al., 2004; Qualls, 2004; Koch et al., 2005) may also occur in groundwater systems, in which microorganisms use ancient organic material trapped within shales as electron donors (Krumholz et al., 1997). In contrast to

\footnotetext{
* Corresponding author. Fax: +49 8931873361.

E-mail address: einsiedl@gsf.de (F. Einsiedl).
}

other aquatic environments, hitherto few studies have addressed molecular characterization and turnover dynamics of groundwater HS on the basis of natural samples (Leenheer et al., 2003). Experiments in marine and lacustrine environments were performed to clarify if isotope effects on organic matter can be used as proxy indicators for microbial degradation processes (Freudenthal et al., 2001; Lehmann et al., 2002). However, these experiments have produced constraining results concerning isotope effects during the microbial degradation of organic matter. Selective loss of specific fractions in the organic matter was observed to create diagenetic shifts in $\delta^{13} \mathrm{C}$ (e.g. Benner et al., 1987), whereas other studies found no isotope fractionation in $\delta^{13} \mathrm{C}$ during alteration (e.g. Schelske and Hodell, 1995).

The study presented here has been performed on a wellcharacterized hydrogeological karst system. Einsiedl (2005) studied the hydrogeology of the karst groundwater system in the Franconian Alb, Southern Germany using artificial 
and environmental tracers. Additionally, biogeochemical issues focusing on sulfur cycle were investigated in this karst area (Einsiedl and Mayer, 2005; Einsiedl et al., 2007). Stable isotope analyses on groundwater sulfate showed that in young groundwater (mean transit times $\leqslant 60$ years) sulfate derived from atmospheric deposition (Einsiedl and Mayer, 2005). Moreover, based on the isotopic composition of groundwater nitrate it was found that nitrate from young groundwater is affected by nitrification processes (Einsiedl and Mayer, 2006).

To verify the hypothesis if microorganisms utilize aquatic HS in the groundwater system, a field study in the karstic catchment area of the Franconian Alb was performed. Molecular signatures may reveal important information on transformation and utilization processes of FAs, which cannot be revealed by conventional analytical tools. Based on organic structural spectroscopy and further geochemical proxies, this field study reports molecular-level resolution evidence of the microbial utilization and transformation of FAs in a natural karst aquifer over historic time scales. To assess the extent of molecular transformation of groundwater HS, water samples from a shallow, oxygendominated karst groundwater system (Einsiedl, 2005) (Fig. 1) were collected during high flow (DOC: $0.44 \mathrm{mM}$ carbon) and base flow (DOC: $0.09 \mathrm{mM}$ carbon).

\section{METHODS}

\subsection{Test field site and field sampling}

The study has been performed on a well-characterized hydrogeological karst system. Around 70 tracer test results (Seiler et al., 1989; Einsiedl, 2005) (Fig. 1) and ${ }^{3} \mathrm{H}$ concentration data in groundwater and precipitation, combined with a dispersion model, were used (Einsiedl and Mayer, 2005) to clarify the hydrogeological conditions of the catchment area and the water flow dynamics of the karst system of the Franconian Alb. These results, combined with water balances, indicate well-defined small catchment areas between approximately 3 and $40 \mathrm{~km}^{2}$ and provide the conditions for observing transformation processes of FAs in this representative groundwater system.

The catchment area of the study site is around $7 \mathrm{~km}^{2}$. Approximately $20 \%$ of the catchment area is used by agriculture, whereas forestry accounts for the majority of the remaining land use. The bedrock is composed of Upper Jurassic carbonates, representing two consecutive cycles of sedimentation with marls on the base overlain by wellbedded limestones. The latter contain reef complexes, which have been converted to dolomite. DOC concentrations during base flow were around $0.09 \mathrm{mM}$ carbon and increase up to around $0.6 \mathrm{mM}$ carbon during high flow conditions. Rainfall was ca. $750 \mathrm{~mm} /$ year and a groundwater recharge of around $130-250 \mathrm{~mm} /$ year was estimated.

A conceptual model for water flow in the karst system is shown in Fig. 1. The karst aquifer is characterized by a fast water flow via conduits (vertical preferential flow) and the epikarst system (horizontal preferential flow). The epikarst connected to conduits acts as a water storage compartment within the vadose zone of the karst system and lies just be- neath the mineral soil. During groundwater recharge conditions the soil-derived seepage water is stored in the epikarst system. From the hydrogeological viewpoint (Einsiedl, 2005) and the results of $\delta^{18} \mathrm{O}$ measurements in groundwater during high flow conditions (Einsiedl et al., 2005), the mean transit time of water in the epikarst was calculated to be between 3 and 4 years. It was therefore straightforward to obtain a representative sample of soil-derived FAs (FA1) from the catchment area independent of the temporal variations in the amount and composition of FA1.

During high flow conditions, the epikarst distributes water via the conduits to the outflow of the spring. Hydrograph separation by chemical tracers revealed a proportion of up to $35 \%$ for the epikarst water contribution to the total runoff during storm runoff events (Einsiedl, 2005), and a DOC concentration of around $20 \mathrm{mg} / \mathrm{L}$ in the epikarst system was estimated. This method effectively sampled a water volume of around $450 \mathrm{~m}^{3}$ and a DOC amount of $2.4 \mathrm{~kg}$ was transported to the vertical preferential flow path of this groundwater system (Einsiedl et al., 2007) during the sampling campaign. During low flow conditions, water flow through the fissured-porous aquifer is expected. A 35 year ${ }^{3} \mathrm{H}$ record yielded mean transit times through the fissuredporous karst aquifer of approximately 60 years for ${ }^{3} \mathrm{H}$ (Einsiedl, 2005).

\subsection{Preparation of natural organic matter samples (FAs and HAs)}

Two samples from the shallow karst aquifer were obtained during high flow (FA1), expected to be rather soil-derived, and base flow conditions (FA2).

During high flow conditions (FA1), a water volume of $100 \mathrm{~L}$ with DOC concentrations of $0.44 \mathrm{mM}$ carbon was $0.45 \mu \mathrm{m}$ field-filtered and pumped at a rate of $19 \mathrm{~L} / \mathrm{h}$ for about $8 \mathrm{~h}$ into stainless steel containers. During base flow conditions, $1500 \mathrm{~L}$ of shallow groundwater, containing DOC concentrations of $0.09 \mathrm{mM}$ carbon (FA2), were sampled using a slightly modified reverse osmosis technique for preconcentration of DOC in the field (Artinger et al., 2000). Schmitt-Kopplin (2005) showed that the reverse osmosis technique for preconcentration of DOC has no appreciable effect on the chemical structure of humic substances. $500 \mathrm{~L}$ of FA2 was transported in stainless steel containers to the laboratory. Repeated preconcentration in the laboratory resulted in three $10 \mathrm{~L}$ samples of DOC-enriched water, which were acidified to a $\mathrm{pH}$ of around 2 by addition of $\mathrm{HCl}$. The isolation of (HS) followed the IHSS standard procedures (Thurman and Malcolm, 1981), using a XAD-8 resin column (Rohm and Haas Co., USA) for sorption at $\mathrm{pH} 2$; the sorbed humic substances were eluted with $0.1 \mathrm{M}$ $\mathrm{NaOH}$. After acidification ( $\mathrm{pH} \mathrm{1,} \mathrm{HCl),} \mathrm{humic} \mathrm{acid} \mathrm{(HA)}$ was precipitated and separated from the supernatant via centrifugation. After three repetitions of this procedure HA was freeze-dried. The supernatant, containing fulvic acids (FAs), was purified by sorption on smaller XAD-8 columns, followed by alkaline elution. Finally, purified FAs were passed through a cation-exchange resin AG 50W-X8 to remove excess salt, and freeze-dried (Table EA1). 


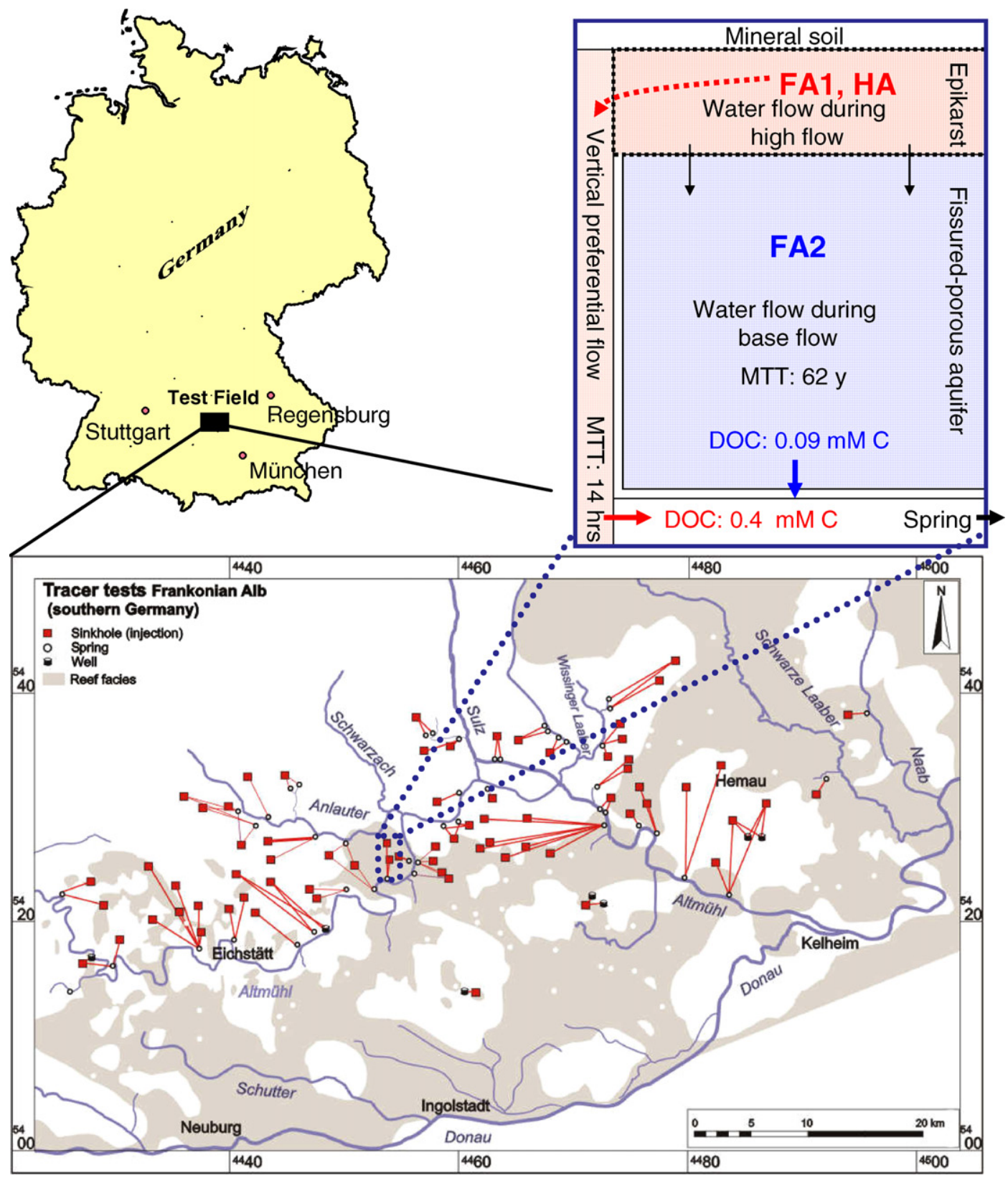

Fig. 1. Conceptual model of water flow during base flow and high flow conditions (Einsiedl, 2005) and the results of the positive tracer tests (red lines) in the catchment area of the Franconian Alb (modified after Seiler et al., 1989): Mean DOC concentrations, modelled mean transit times MTT; key data of catchment area: rainfall: $0.75 \mathrm{~m} / \mathrm{a}$; evapotranspiration: ca. $0.5-0.6 \mathrm{~m} / \mathrm{a}$; groundwater recharge $0.15-0.25 \mathrm{~m} / \mathrm{a}$.

\subsection{Isotope measurements $\left(\delta^{13} \mathrm{C}\right.$ FAs), asymmetrical flow} field-flow fractionation (AFFFF), radiocarbon content of FAs $\left({ }^{14} \mathrm{C}_{\mathrm{FAs}}\right)$, NMR spectroscopy and FTICR mass spectrometry

Information about analytical details can be found in the Electronic Annex.

\section{RESULTS AND DISCUSSION}

The ${ }^{14} \mathrm{C}$ contents of the epikarst water FAs (FA1: 120.6 pmc), which is considered mostly originated from soil, and the base flow water FAs (FA2: 112.1 pmc) indicate radio- carbon ages lower than 50 years and support an identical origin, demonstrating FAs cannot be attributed to release from the bedrock. $\delta^{13} \mathrm{C}$ values obtained for FA1 and FA2 were $-27 \pm 0.2 \%$ in line with $\delta^{13} \mathrm{C}$ values of $\mathrm{C}-3$ plants, indicating related sources of FAs. The content of FAs infiltrating into the groundwater system was estimated by asymmetrical flow field-flow fractionation studies (Wolf et al., 2005) (AFFFF with short-range UV detection and FAs calibration) and yielded a contribution of $55 \%$ FAs to the entire DOC (Einsiedl et al., 2007). The contribution of peak flow extracted HAs (data not shown), with ${ }^{1} \mathrm{H}$ NMR characteristics astonishingly similar to peat HAs, 
shown in Hertkorn et al. (2002b), was around 5\%. Mass balances computed from hydrogeological data showed mineralization of $50-60 \%$ of FAs in the deeper part of the shallow aquifer (Heinrichs, 1987). These data suggest that FAs contribute with increasing proportions to the deeper groundwater DOC whereas HAs, with a structure more closely related to biomolecules, probably degrade at a higher rate (Hertkorn et al., 2002a). Alternative mechanisms of removal such as sorption to the mineral soil (Feng et al., 2005) and coagulation by metal ions such as $\mathrm{Ca}^{2+}, \mathrm{Fe}^{3+}$ and $\mathrm{Al}^{3+}$ (Christl and Kretzschmar, 2007) operate more effectively for HAs than FAs.

During the transport through a karst groundwater system, extensive molecular transformation of soil-derived FA1 to FA2 led to a striking depletion of oxygen from a wide variety of carbon-bearing environments. Nuclear magnetic resonance (NMR) spectra indicate the disappearance of carbohydrates, which comprise one fifth of (nonexchangeable) proton and carbon NMR integrals, from FA1 (Fig. 2A-E); the fraction of non-exchangeable OC-H protons in FA2 declines to near ten percent, most of which are non-carbohydrate related according to ${ }^{1} \mathrm{H}$ NMR line shape and HSQC cross peak positions (Fig. 2A and F). In FA2 aromatics have been depleted from almost all kinds of direct $\left(\mathrm{C}_{\mathrm{ar}}-\mathrm{O}\right)$ and remote $\left(\mathrm{C}_{\mathrm{ar}}-\mathrm{COX} ; \mathrm{X}=\mathrm{OH}, \mathrm{OR}\right)$ oxygen substitution, a common and even abundant feature of FA1. Direct oxygenation of aromatic rings in FA1 is represented by evident phenolic ${ }^{13} \mathrm{C}$ NMR resonances (ipso$\mathrm{C}_{\mathrm{ar}} \mathrm{O}$; quaternary carbon only, $\delta_{\mathrm{C}}: 152 \pm 8$ ppm; Fig. $2 \mathrm{C}$ and D) and by distinct ortho and para oxygenated aromatic carbon NMR signals $\left(\delta_{\mathrm{C}}<125 \mathrm{ppm}\right.$; quaternary and methine carbon; Fig. 2C and E). In addition, HSQC cross peak positions reflect extensive oxygen $\left(\mathrm{C}_{\mathrm{ar}}-\mathrm{O}\right)$ aromatic ring substitution because of major upfield chemical shift displacements of hydrogen in both, ortho and para positions as compared with benzene $\mathrm{C}_{6} \mathrm{H}_{6}\left(\delta\left({ }^{1} \mathrm{H} /{ }^{13} \mathrm{C}\right): 7.25 /\right.$ $128.0 \mathrm{ppm})$ as well as complementary carbonyl derivative $\left(\mathrm{C}_{\mathrm{ar}}-\mathrm{COX}\right)$ aromatic ring substitution (Figs. 2C and $\mathrm{G}, 3$ and 4), indicated by downfield chemical shift displacement of ortho hydrogen atoms, caused by chemical shift anisotropy of the carbonyl bond. Downfield shift displacements also apply for hydrogen and carbon atoms in ortho and para positions because of electron-withdrawal (Perdue et al., 2007) Accordingly, a more even distribution of aromatic methine carbon ranging from $\delta_{\mathrm{C}}=107$ to $136 \mathrm{ppm}$ in FA1 was altered into a triangular envelope extending from $\delta_{\mathrm{C}}=113$ to $135 \mathrm{ppm}$ in FA2, with a distinct maximum intensity at $\delta_{\mathrm{C}}=129$ ppm (Fig. 2E).

An in-depth study of aromatic substitution patterns obtained from an inverse increment analysis (SPARIA, substitution patterns in aromatic rings by increment analysis (Perdue et al., 2007)) of the HSQC cross peaks of (a) FA1 and (b) FA2 revealed extensive alteration of aromatic structures between FA1 and FA2. Most obviously, HSQC cross peak positions for FA1 (A1-A18, Fig. 3A) only sparsely coincide with those derived from FA2 (B1-B6 and C1C10; Fig. 3B), indicating substantial degradation of FA1 and resynthesis of novel aromatic compounds in FA2. The selected HSQC cross peaks, assigned to the substituent classes hydrogen $\mathrm{H}$ (deep green), neutral carbon substituent $\mathrm{R}$ (light green), electron-withdrawing carbonyl derivative COR (blue), and electron-donating oxygen derivative OR
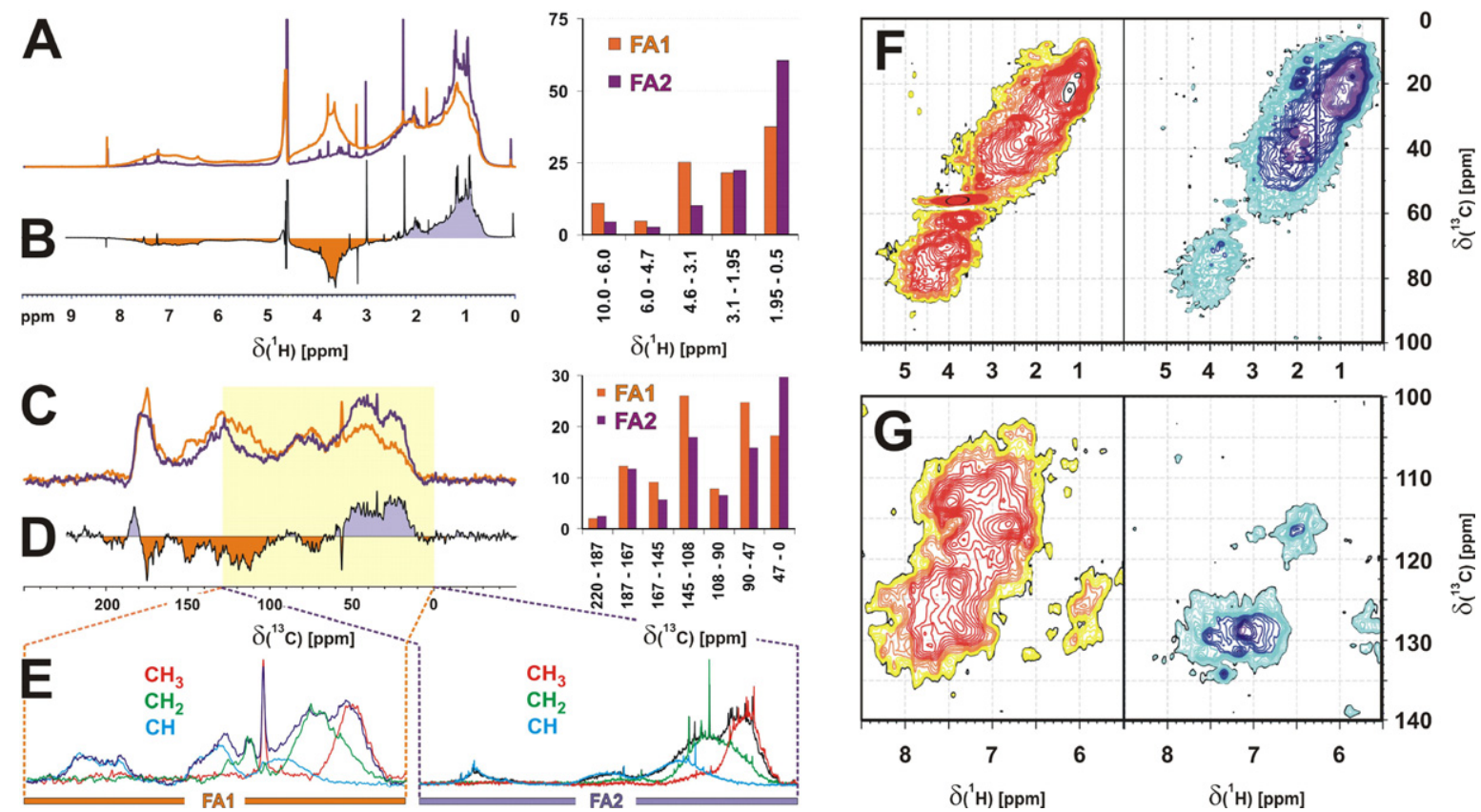

Fig. 2. (A) ${ }^{1} \mathrm{H}$ NMR spectra (left) and section integrals (right) of non-exchangeable protons in FA1 (orange) and FA2 (purple); (B) difference ${ }^{1}$ H NMR spectrum of FA2 (positive) minus FA1 (negative); (C) ${ }^{13} \mathrm{C}$ NMR spectra (left) and section integrals (right) of FA1 (orange) and FA2 (purple); (D) difference ${ }^{13} \mathrm{C}$ NMR spectrum of FA2 (positive) minus FA1 (negative); (E) multiplicity-edited ${ }^{13} \mathrm{C}$ NMR carbon traces of FA1 (left) and FA2 (right); methyl: red; methylene: green; methine: blue; sum of $\mathrm{CH}_{1,2,3}$ : black; (F and G) ${ }^{1} \mathrm{H},{ }^{13} \mathrm{C}$ HSQC NMR spectra (F: aliphatic, G: aromatic section) of FA1 (left) and FA2 (right), see also Figs. 3 and 4. 


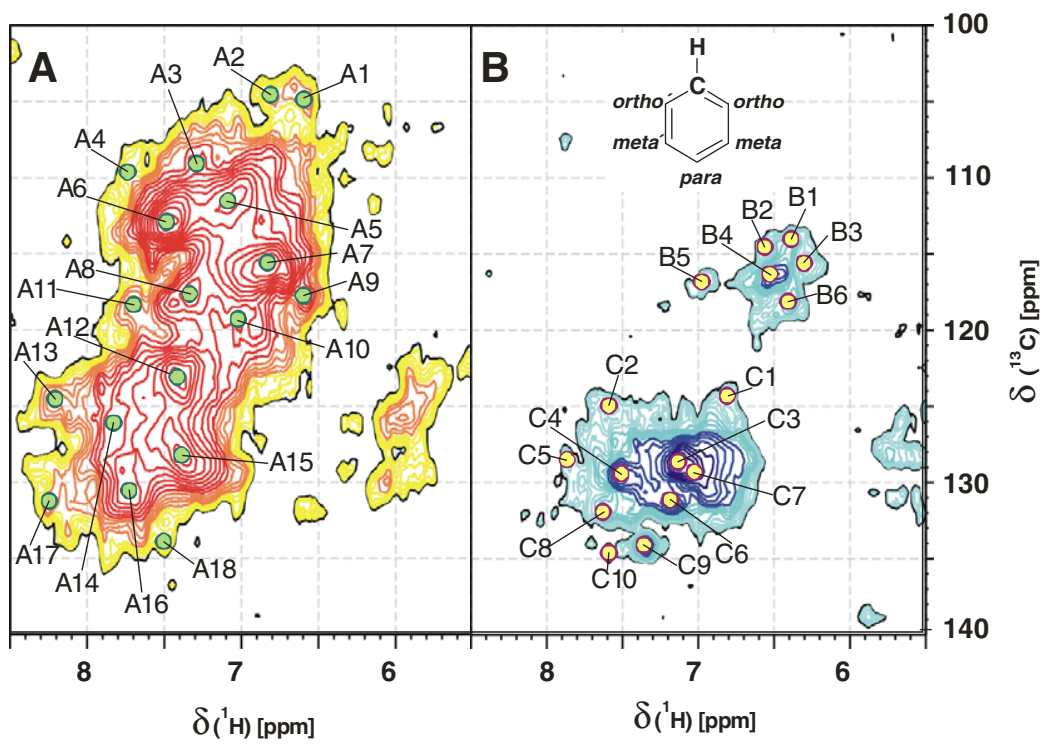

Fig. 3. Aromatic section of ${ }^{1} \mathrm{H},{ }^{13} \mathrm{C}$ HSQC cross peaks of (A) FA1 and (B) FA2 with positions of main cross peaks indicated for in-depth SPARIA, (substitution patterns in aromatic rings by increment analysis) (Perdue et al., 2007) of aromatic substitution patterns (cf. Fig. 4).

(orange) by means of SPARIA analysis are depicted in Fig. 4. It is clearly seen, that the HSQC cross peaks A1A18 (FA1) exhibit substantial shares of oxygen-containing substituents COR and OR, corresponding to multiple oxygen atoms per aromatic ring. In general, aromatic compounds in FA1 are more oxygenated than those in FA2. FA2-derived HSQC cross peaks B1-B6 fall outside the chemical shift window typical of substituted monoaromatic rings (Perdue et al., 2007) and could indicate the presence of newly synthesized five-membered ring heterocycles and carotenoid compounds in FA2.

Aromatic carboxylic acids in FA1 have been replaced by near identical amounts of aliphatic acids in FA2 as indicated by downfield displacement of corresponding ${ }^{13} \mathrm{C}$ NMR signals (Fig. 2D). Methoxyl carbon (FA1: 19\% of methyl carbon) has almost entirely disappeared in FA2, just as methylene carbon atoms in ethers and esters (FA1: 25\% of methylene carbon); the proportion of methine carbon in the forms of $C_{\mathrm{ar}}-\mathrm{H} / \mathrm{OC}-\mathrm{H} / \mathrm{CC}-\mathrm{H}$ has been altered from a ratio of 39/32/29 in FA1 to 21/22/57 in FA2 (Fig. 2E). All intense ${ }^{1} \mathrm{H},{ }^{13} \mathrm{C}$ HSQC cross peaks in FA1 representing $\mathrm{OC}_{\mathrm{al}}-\mathrm{H}$ with $\delta_{\mathrm{C}}>80 \mathrm{ppm}$ and $\delta_{\mathrm{C}}>4.2 \mathrm{ppm}$ (i.e. ethers and esters) have almost disappeared in FA2 (Fig. 2F). In summary, the transformation of FA1 into FA2 has considerably increased the proportion of aliphatic, carbon- and hydrogen-substituted chemical environments for methyl, methylene and methine and aromatic carbon atoms. Extensive degradation of polysaccharides (Watt et al., 1996) and lignin-derived moieties at a fairly early stage of FA diagenesis as observed by NMR (Fig. 2) was also found in decomposition experiments of different vascular plant leaves (Opsahl and Benner, 1997).

Negative electrospray ionization Fourier transform ion cyclotron FTICR mass spectra of FA1 and FA2 at unit resolution exhibit near Gaussian envelopes of mass distribution with seemingly minor displacements of the intensityweighed average $\mathrm{m} / \mathrm{z}$ values (FA1: $413 \mathrm{~m} / \mathrm{z}$; FA2: $384 \mathrm{~m} /$ $z$ ). The intensity-based envelope at half height is narrowed by $30 \mathrm{~m} / \mathrm{z}$ in case of $\mathbf{F A 2}$ and at higher masses (in excess of $470 \mathrm{~m} / \mathrm{z}$ ), FA2 shows fewer and less intense signals than FA1 (Fig. 5A and B). This is in line with AFFFF data (Wolf et al., 2005), which indicated increasing shares of progressively smaller molecules during transition from epikarst to shallow aquifer FA (Fig. 6).

The $\mathrm{CH}_{2}$-based Kendrick mass defect analysis (Hughey et al., 2001) of the most intense mass spectral peaks provided 458 molecular compositions common to both FA1 and FA2, 482 unique to FA1, and 224 unique to FA2, respectively (Fig. 5C). The combined 1164 molecular compositions were all best described by molecular formulae $\mathrm{C}_{n} \mathrm{H}_{m} \mathrm{O}_{q}$ (in line with the low content of nitrogen and sulfur in both FA1 and FA2, Table EA1) and occupied about 90 $\mathrm{CH}_{2}$-based series of identical Kendrick mass defects, which were typically $13 \pm 3$ members long and rather continuous (i.e. unbroken; Fig. 5C). The displacement of at least more than half of the observed molecular compositions clearly indicates extensive alterations of the molecular-level chemical environments during the transformation of FA1 into FA2.

In the mass range below $470 \mathrm{~m} / \mathrm{z}$, FA2 molecules of identical mass exhibit smaller $\mathrm{CH}_{2}$-based Kendrick mass defects (KMD) than those in FA1 and vice versa, indicating a likely oxygen deficiency and/or increased degree of hydrogenation of FA2 molecules. Eight series of unique KMD with more than 50 members, solely occurring in FA2 and mostly related by differences in KMD of $36.4 \mathrm{mDa}$ (KMD: 0.2299, $0.2663,0.2892,0.3255,0.3619,0.3982,0.4346,0.4709)$ indicated the formation of novel classes of compounds, not present in FA1 (Figs. 5C and 7). Interestingly, the considerable majority of this newly formed series of molecules in FA2 are found in the uppermost right corner of the van Krevelen diagram, indicating rather saturated and still oxygen-rich molecules (Fig. 7). The formation of novel classes of compounds again suggests that microbial processes 


\begin{tabular}{|c|c|c|c|c|c|c|c|c|c|}
\hline \multicolumn{10}{|c|}{ FA1 } \\
\hline peak & $\begin{array}{c}\delta\left({ }^{1} \mathrm{H}\right) \\
{[\mathrm{ppm}]}\end{array}$ & $\begin{array}{l}\delta\left({ }^{13} \mathrm{C}\right) \\
{[\mathrm{ppm}]}\end{array}$ & ortho & meta & para & meta' & ortho' & percent & ne \\
\hline A1 & 6.57 & 104.6 & & & & & & 27 & 67 \\
\hline $\mathrm{A} 2$ & 6.79 & 104.4 & & & & & & 45 & 20 \\
\hline A3 & 7.28 & 108.7 & & & & & & 37 & 45 \\
\hline A4 & 7.73 & 109.5 & & & & & & 50 & 2 \\
\hline A5 & 7.08 & 111.4 & & & & & & 32 & 38 \\
\hline A6 & 7.49 & 112.6 & & & & & & 41 & 59 \\
\hline A7 & 6.82 & 115.5 & & & & & & 19 & 52 \\
\hline A8 & 7.33 & 117.4 & & & & & & 17 & 59 \\
\hline A9 & 6.57 & 117.6 & & & & & & 33 & 36 \\
\hline $\mathrm{A} 10$ & 7.13 & 120.2 & & & & & & 31 & 78 \\
\hline $\mathrm{A} 11$ & 7.39 & 118.2 & & & & & & 17 & 78 \\
\hline $\mathrm{A} 12$ & 7.42 & 122.8 & & & & & & 14 & 114 \\
\hline A13 & 8.21 & 124.2 & & & & & & 25 & 75 \\
\hline A14 & 7.83 & 126.0 & & & & & & 14 & 122 \\
\hline A15 & 7.38 & 128.0 & & & & & & 28 & 43 \\
\hline A16 & 7.74 & 130.3 & & & & & & 33 & 812 \\
\hline A17 & 8.25 & 131.1 & & & & & & 41 & 87 \\
\hline A18 & 7.50 & 133.6 & & & & & & 52 & 48 \\
\hline \multicolumn{10}{|c|}{ FA2 } \\
\hline peak & $\begin{array}{c}\delta\left({ }^{1} \mathrm{H}\right) \\
{[\mathrm{ppm}]}\end{array}$ & $\begin{array}{l}\delta\left({ }^{13} \mathrm{C}\right) \\
{[\mathrm{ppm}]}\end{array}$ & ortho & meta & para & meta' & ortho' & percent & ne \\
\hline B1 & 6.39 & 113.9 & & & & & & 36 & 33 \\
\hline B2 & 6.53 & 114.6 & & & & & & 36 & 29 \\
\hline B3 & 6.29 & 115.3 & & & & & & 100 & 10 \\
\hline B4 & 6.52 & 116.0 & & & & & & 23 & 26 \\
\hline B5 & 6.97 & 116.6 & & & & & & 24 & 104 \\
\hline B6 & 6.39 & 117.9 & & & & & & 36 & 14 \\
\hline $\mathrm{C} 1$ & 6.79 & 124.1 & & & & & & 33 & 30 \\
\hline $\mathrm{C} 2$ & 7.58 & 124.8 & & & & & & 21 & 63 \\
\hline C3 & 7.12 & 128.3 & & & & & & 19 & 36 \\
\hline $\mathrm{C} 4$ & 7.51 & 129.1 & & & & & & 29 & 59 \\
\hline C5 & 7.86 & 128.3 & & & & & & 28 & 97 \\
\hline C6 & 7.17 & 131.0 & & & & & & 28 & 42 \\
\hline $\mathrm{C7}$ & 7.05 & 128.9 & & & & & & 43 & 30 \\
\hline $\mathrm{C} 8$ & 7.62 & 131.6 & & & & & & 33 & 93 \\
\hline $\mathrm{C9}$ & 7.34 & 133.8 & & & & & & 36 & 56 \\
\hline $\mathrm{C} 10$ & 7.59 & 134.4 & & & & & & 87 & 15 \\
\hline \multicolumn{10}{|c|}{ aromatic substitution, composed of hydrogen } \\
\hline \multicolumn{10}{|c|}{ aromatic substitution, composed of neutral carbon substituents } \\
\hline & \multirow{2}{*}{\multicolumn{9}{|c|}{ aromatic substitution, composed of electron-withdrawing carbonyl derivative substituents }} \\
\hline & & & & & & & & & \\
\hline
\end{tabular}

Fig. 4. Aromatic substitution patterns as deduced from inverse increment analysis (SPARIA, substitution patterns in aromatic rings by increment analysis (Perdue et al., 2007)) of the HSQC cross peaks of (Fig. 3A) FA1 and (Fig. 3B) FA2. The most likely substituents patterns are indicated here, arranged according to position (Fig. 3B) and in color: hydrogen $\mathrm{H}$ (deep green), neutral carbon substituent $\mathrm{R}$ (light green), electron-withdrawing carbonyl derivative COR (blue), and electron-donating oxygen derivative OR (orange) substituents. The most likely patterns are extracted from the total number of SPARIA hits within a $0.1 \mathrm{ppm}$ window in ${ }^{1} \mathrm{H}$ and $1.0 \mathrm{ppm}$ in ${ }^{13} \mathrm{C}$ NMR frequency (with the counts given in the right column), and the weight percentage of the corresponding color representation to the total number of SPARIA hits is indicated in the second column from the right.

rather than sorption to the geological matrix control the transformation of FA1 into FA2.

The compositional spaces occupied in van Krevelen diagrams (Visser, 1983) by FA1 alone, the common FA1/FA2 compositional space, and that occupied by FA2 alone experience continual displacement towards decreased $\mathrm{O} / \mathrm{C}$ and increased $\mathrm{H} / \mathrm{C}$ ratios (Figs. 5D and 8 ) which are indicative of hydrogenation and deoxygenation across the entire bandwidth of $\mathrm{C}_{n} \mathrm{H}_{m} \mathrm{O}_{q}$ compositional space during transformation from FA1 into FA2. The depletion of aromatics during processing of FA1, most of which carry multiple oxygen substitution, as identified by NMR (Figs. 3 and 4 ), represents one of the key processes contributing to the formal hydrogenation deduced from the van Krevelen diagram.
Thus, the most probable explanation of the molecularlevel analysis involves the almost complete conversion of a plant-derived, lignin-, phenol- and carbohydrate-rich natural organic matter (NOM, FA1) into microbially-derived, structurally entirely different, deoxygenated and dearomatized, alicyclic polycarboxylic acid type NOM (FA2) (Leenheer et al., 2003; Hertkorn et al., 2006) during the passage through the karst aquifer.

In this study, a detailed hydrogeological and geochemical investigation of a karst groundwater system in Southern Germany, in conjunction with a characterization of FAs via molecular-level organic structural spectroscopy (NMR und FTICR mass spectrometry), enabled a comprehensive description of microbial utilization and transformation processes of soil-derived FAs. Mineralization of FAs in 

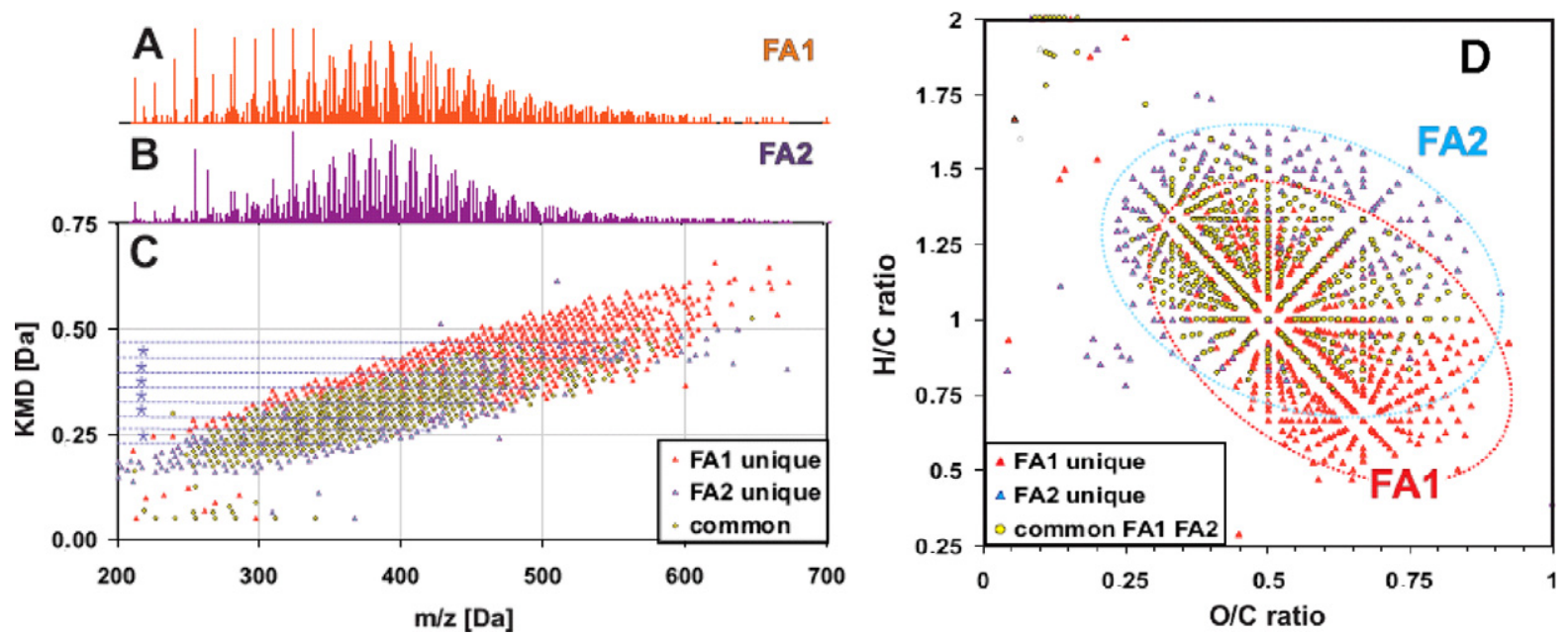

Fig. 5. (A and B) 12 T FTICR mass spectra of FA1 (orange, top) and FA2 (purple, bottom); (C) $\mathrm{CH}_{2}$-based Kendrick mass defect analysis of $\mathrm{C}_{n} \mathrm{H}_{m} \mathrm{O}_{q}$ molecules unique to FA1 (orange, ne =482), unique to FA2 (blue, ne =224) and common to both FA1 and FA2 (yellow, ne = 458); the dotted line denotes eight series of unique KMD, representing newly synthesized molecules in FA2; the denoted (*) difference in KMD is $36.4 \mathrm{mDa}$; (D) Van Krevelen diagram of FA1 (red), FA2 (blue); indicating progressive deoxygenation and hydrogenation during aging.

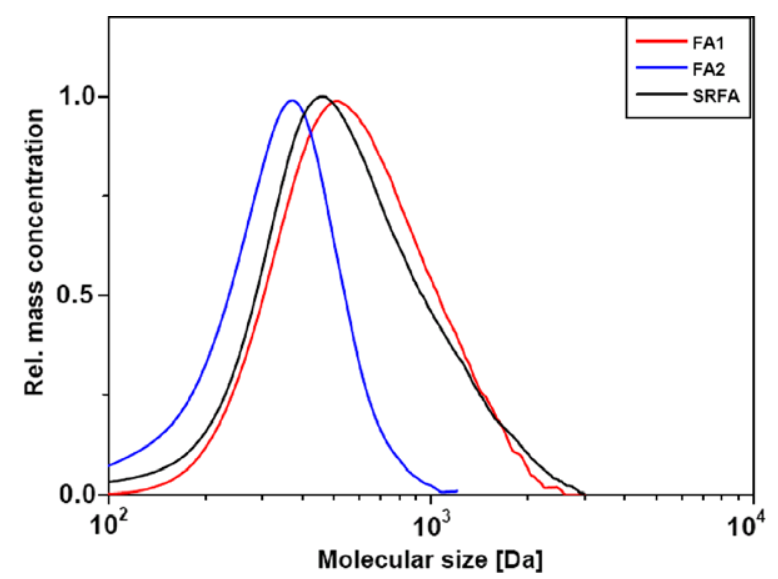

Fig. 6. Molecular size distribution of FA1 and FA2 and Suwannee River FA (SRFA) measured by AFFFF.

groundwater systems is probably the most important removal process, occurring with turnover rates of decades. Similar processes, i.e. formation of refractory DOM from rapid degradation of labile compounds, have also been shown to occur in the marine environment (Hansell et al., 2004). FAs exhibit irreversible sorption to calcite surfaces (Lee et al., 2005), blocking all calcite surface sites over decades in the carbonate aquifer. Therefore, FAs can be considered as a conservative tracer (Buckau et al., 2000) in groundwater systems of the Franconian Alb over historical and geological time scales. Even in the absence of photochemistry (Opsahl and Benner, 1997; Kujawinski et al., 2004) and abiotic redox NOM-mineral chemistry (Wang et al., 1997), which are considered as well established fast and effective NOM degradation reactions, a rapid and near complete molecular-level turnover of FAs was observed. Since our investigation area provides little likelihood of abiotic reactions, the observed disappearance of oxygen from a vast array of aliphatic and aromatic chemical environments of this representative FAs is most probably the consequence

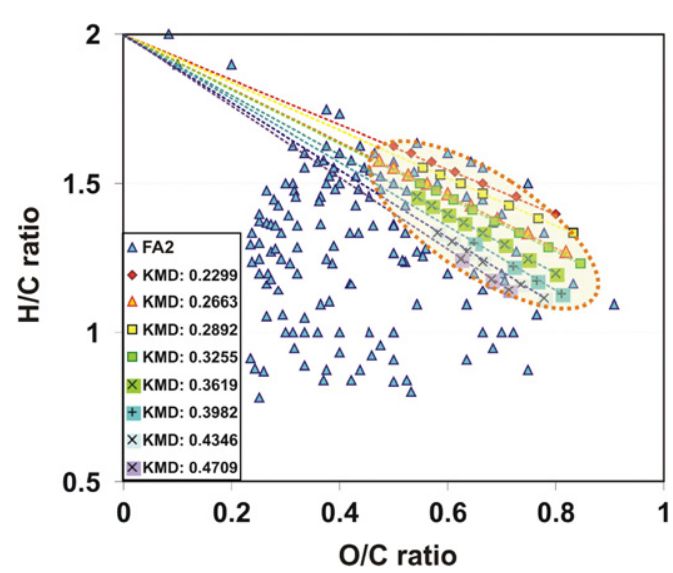

Fig. 7. Van Krevelen diagram of identified molecular formulae $\mathrm{C}_{n} \mathrm{H}_{m} \mathrm{O}_{q}$ occurring solely in FA2, indicating newly formed series of compounds in the early diagenesis of FA, introduced in the Kendrick mass analysis (Fig. 5C), and displayed according to methylene-based Kendrick mass defects. The highlighted molecules occupy the range of elemental compositions within the dotted orange ellipsoid and represent mainly rather oxygen-rich and hydrogenated molecular compositions.

of biotic utilization. Though extensive depletion of oxygen has been observed upon transformation of FA1 into FA2, oxidation has nevertheless taken place and highly oxidized mineralization products such as $\mathrm{CO}_{2}$ and $\mathrm{H}_{2} \mathrm{O}$ have been necessarily formed. This rapid turnover of a representative organic material often considered refractory under natural conditions provides the key to understanding the disappearance of DOC in groundwater systems and should be considered the rule rather than the exception.

\section{CONCLUSION}

Our results show a near complete turnover of FA within decades in the groundwater system. The extraordinary differences between FA1 and FA2 at molecular-level structural 


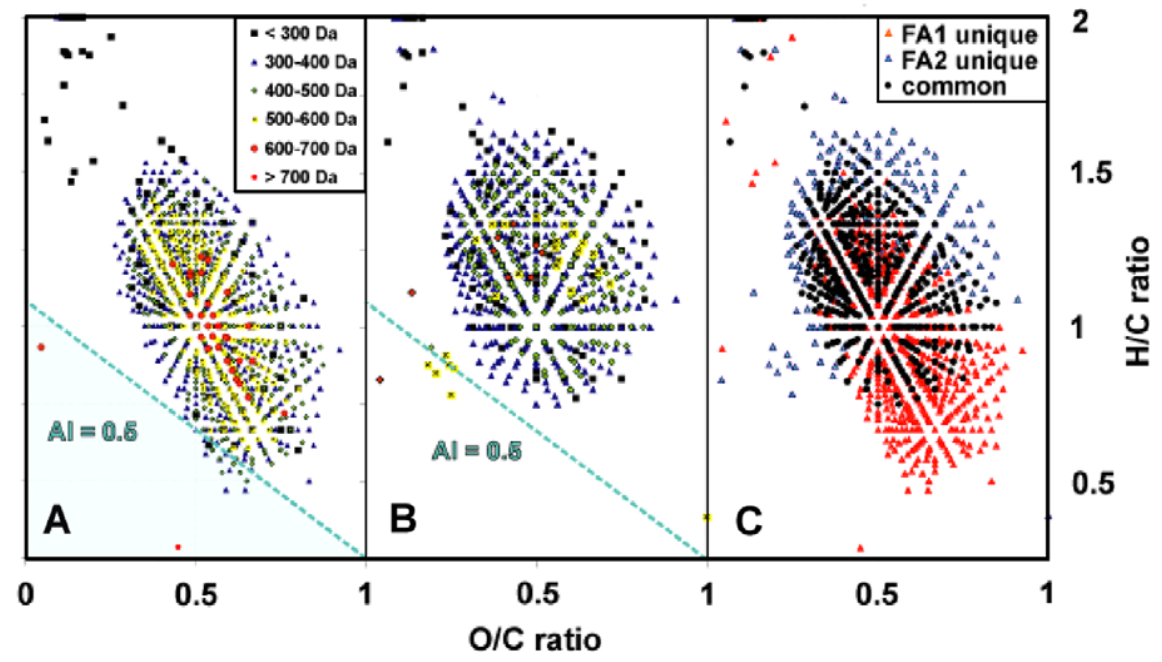

Fig. 8. Van Krevelen diagram of $\mathrm{C}_{n} \mathrm{H}_{m} \mathrm{O}_{q}$ molecular compositions in FA1 and FA2 as derived from FTICR mass spectra; (A) unique to FA1 (mass edited, with aromaticity index $\mathrm{AI}=0.5$ given), (B) unique to FA2 (mass edited, with aromaticity index $\mathrm{AI}=0.5$ given) and $(\mathrm{C})$ common to both FA1 and FA2, FA1 = FA2 (black), FA1 (red) and FA2 (blue). The aromaticity index AI provides a threshold, which unambiguously indicates occurrence of aromatic molecules in absence of cumulated $\pi$-bond and triple bonds (Koch and Dittmar, 2006); AI values in excess of 0.5 (cf. blue triangle in (A)) indicate certain presence of aromatic rings in FA1 (Koch and Dittmar, 2006).

resolution were only revealed by high-performance non-target organic structural spectroscopy. Even fairly advanced analytical tools at the level of standard ${ }^{13} \mathrm{C}-\mathrm{CP} / \mathrm{MAS}$ solid-state spectroscopy and unit-resolution mass spectrometry would have failed to detect these extensive changes because of intrinsic averaging (Hertkorn et al., in press). Based on this novel perspective, molecular-level alterations of such magnitude and rapidity must be considered as commonplace in the processing of "refractory" NOM, which then has to be perceived, in contrast to conventional wisdom, as a rather more active participant in the global carbon cycle than hitherto postulated.

Our data set is directly applicable to earlier results focusing on biogeochemical processes affecting groundwater sulfate and nitrate. We found that sulfate reduction and denitrification have occurred in the porous rock matrix of the karst groundwater system with long mean transit times ( $>60$ years). Since Dittmar and Lara (2001) and Benner et al. (1987) have shown that the degradation of complex organic compounds continues under sulfate-reducing conditions at a lower rate compared to microbial degradation processes of organic matter under oxic conditions, we suggest that FA act as electron donor for sulfate-reducing microorganisms and denitrifiers in the porous rock matrix. The porous rock matrix is characterized by long mean transit times up to some hundreds of years (Einsiedl and Mayer, 2005), and could represent the habitat to facilitate anoxic processes in the predominantly oxic zone of the karst system by the microbial degradation of FA over historical time scales.

\section{APPENDIX A. SUPPLEMENTARY DATA}

Supplementary data associated with this article can be found, in the online version, at doi:10.1016/j.gca.2007. 09.024 .

\section{REFERENCES}

Abbt-Braun G. F. and Frimmel F. H. (2002). In Refractory Organic Substances in the Environment (eds. F. H. Frimmel, J. Jahnel and S. Hesse). Wiley-VCH.

Artinger R., Buckau G., Geyer S., Fritz P., Wolf M. and Kim J. I. (2000) Characterization of groundwater humic substances: influence of sedimentary organic carbon. Appl. Geochem. 15, 97-116.

Benner R., Fogel M. L., Sprague E. K. and Hodson R. E. (1987) Depletion of ${ }^{13} \mathrm{C}$ in lignin and its implications for stable carbon isotope studies. Nature 329, 708-710.

Bianchi T. S., Freer M. E. and Wetzel R. G. (1996) Temporal and spatial variability, and the role of dissolved organic carbon (DOC) in methane fluxes from the Sabine River floodplain (southeast Texas, USA). Archiv für Hydrobiologie 136, 261-287.

Buckau G., Artinger R., Kim J. I., Geyer S., Fritz P., Wolf M. and Frenzel B. (2000) Development of climatic and vegetation conditions and the geochemical and isotopic composition in the Franconian Albvorland aquifer system. Appl. Geochem. 15, 1191-1201.

Christl I. and Kretzschmar R. (2007) C-1s NEXAFS spectroscopy reveals chemical fractionation of humic acid by cation-induced coagulation. Environ. Sci. Technol. 41, 1915-1920.

Dittmar T. and Lara R. J. (2001) Molecular evidence for lignin degradation in sulfate-reducing mangrove sediments (Amazonia, Brazil). Geochim. Cosmochim. Acta 65, 1417-1428.

Einsiedl F. (2005) Flow system dynamics and water storage in a fissured-porous karst aquifer. J. Hydrol. 312, 312-321.

Einsiedl F., Maloszewski P. and Stichler W. (2005) Estimation of denitrification potential in a karst aquifer using the ${ }^{15} \mathrm{~N}$ and ${ }^{18} \mathrm{O}$ isotopes of nitrate. Biogeochemistry 72, 67-86.

Einsiedl F. and Mayer B. (2005) Sources and processes affecting sulphate in a karstic groundwater system of the Franconian Alb, Southern Germany. Environ. Sci. Technol. 39, 7118-7125.

Einsiedl F. and Mayer B. (2006) Hydrodynamic and microbial processes controlling nitrate in a fissured porous aquifer. Environ. Sci. Technol. 40, 6697-6702. 
Einsiedl F., Schäfer T. and Northrup P. (2007) Combined sulfur Kedge XANES spectroscopy and stable isotope analyses of fulvic acids and groundwater sulfate identify sulfur cycling in a karstic catchment area. Chem. Geol. 238, 268-276.

Feng X., Simpson A. J. and Simpson M. J. (2005) Chemical and mineralogical controls on humic acid sorption to clay mineral surfaces. Org. Geochem. 36, 1553-1566.

Freudenthal T., Wagner T., Wenzhofer F., Zabel M. and Wefer G. (2001) Early diagenesis of organic matter from sediments of the eastern subtropical Atlantic: evidence from stable nitrogen and carbon isotopes. Geochim. Cosmochim. Acta 65, 1795-1808.

Hansell D. A., Kadko D. and Bates N. R. (2004) Degradation of terrigenous dissolved organic carbon in the Western Arctic Ocean. Science 304, 858-861.

Heinrichs G. (1987) DOC mass balance of the Franconian Alb. GSF-JB-Inst. Hydrol., 36-46.

Hertkorn N., Benner R., Frommberger M., Schmitt-Kopplin P., Witt M., Kaiser K., Kettrup A. and Hedges J. I. (2006) Characterization of a major refractory component of marine dissolved organic matter. Geochim. Cosmochim. Acta 70, 2990-3010.

Hertkorn N., Claus H., Schmitt-Kopplin Ph., Perdue E. M. and Filip Z. (2002a) Utilization and transformation of aquatic humic substances by autochthonous microorganisms. Environ. Sci. Technol. 36, 4334-4345.

Hertkorn N., Permin A., Perminova I., Kovalevskii D., Yudov M., Petrosyan V. and Kettrup A. (2002b) Comparative analysis of partial structures of a peat humic and fulvic acid using one- and two-dimensional nuclear magnetic resonance spectroscopy. $J$. Environ. Qual. 31, 375-387.

Hertkorn, N., Ruecker, C., Meringer, M., Gugisch, R., Frommberger, M., Perdue, E. M., Witt, M. and Schmitt-Kopplin, Ph. (in press). High-precision frequency measurements: indispensable tools at the core of molecular-level analysis of complex systems. Anal. Bioanal. Chem., doi:10.1007/s00216-007-1577-4.

Hughey C. A., Hendrickson C. L., Rodgers R. P., Marshall A. G. and Qian K. N. (2001) Kendrick mass defect spectrum: a compact visual analysis for ultrahigh-resolution broadband mass spectra. Anal. Chem. 73, 4676-4681.

Koch B. P., Harder J., Lara R. J. and Kattner G. (2005) The effect of selective microbial degradation on the composition of mangrove derived pentacyclic triterpenols in surface sediments. Org. Geochem. 36, 273-285.

Koch B. P. and Dittmar T. (2006) From mass to structure: an aromaticity index for high-resolution mass data of natural organic matter. Rapid Commun. Mass Spectrom. 20, 926-932.

Krumholz L. R., McKinley J. P., Ulrich G. A. and Suflita J. M. (1997) Confined subsurface microbial communities in Cretaceous rock. Nature 386, 64-66.

Kujawinski E. B., Del Vecchio R., Blough N. V., Klein G. C. and Marshall A. G. (2004) Probing molecular-level transformations of dissolved organic matter: insights on photochemical degradation and protozoan modification of DOM from electrospray ionization Fourier transform ion cyclotron resonance mass spectrometry. Mar. Chem.: New Approaches in Marine Organic Biogeochemistry: A Tribute to the Life and Science of John I. Hedges 92, 23-37.

Lee Y. J., Elzinga E. J. and Reeder R. J. (2005) Cu(II) adsorption at the calcite-water interface in the presence of natural organic matter: kinetic studies and molecular-scale characterization. Geochim. Cosmochim. Acta 69, 49-61.

Leenheer J. A., Wershaw R. L., Brown G. K. and Reddy M. M. (2003) Characterization and diagenesis of strong-acid carboxyl groups in humic substances. Appl. Geochem. 18, 471-482.

Lehmann M. F., Bernasconi S. M., Barbieri A. and McKenzie J. A. (2002) Preservation of organic matter and alteration of its carbon and nitrogen isotope composition during simulated and in situ early sedimentary diagenesis. Geochim. Cosmochim. Acta 66, 3573-3584.

Lovley D. R., Fraga J. L., Coates J. D. and Blunt-Harris E. L. (1999) Humics as an electron donor for anaerobic respiration. Environ. Microbiol. 1, 89-98.

Ogawa H., Fukuda R. and Koike I. (1999) Vertical distributions of dissolved organic carbon and nitrogen in the Southern Ocean. Deep Sea Res. I, Oceanogr. Res. Pap. 46, 1809-1826.

Opsahl S. and Benner R. (1997) Distribution and cycling of terrigenous dissolved organic matter in the ocean. Nature 386, 480-482.

Perdue E. M., Hertkorn N. and Kettrup A. (2007) Substitution patterns in aromatic rings by increment analysis. Model development and application to natural organic matter. Anal. Chem. 79, 1010-1021.

Qualls R. G. (2004) Biodegradability of humic substances and other fractions of decomposing leaf litter. Soil Sci. Soc. Am. J. 68, 1705-1712.

Schelske C. L. and Hodell D. A. (1995) Using carbon isotopes of bulk sedimentary organic matter to reconstruct the history of nutrient loading and eutrophication in Lake Erie. Limnol. Oceanogr. 40, 918-929.

Schmitt-Kopplin, Ph. (2005) Capillary electrophoretic techniques coupled to mass spectrometry for the characterization of NOM. In Advanced Characterization of Natural Organic Matter symposium at the Fall, August 28th-September 1st, National ACS Meeting, Washington, DC, USA.

Seiler K.-P., Maloszewski P. and Behrens H. (1989) Hydrodynamic dispersion in karstified limestones and dolomites in the Upper Jurassic of the Franconian Alb, FRG. J. Hydrol. 108, 235-247.

Thurman E. M. and Malcolm R. L. (1981) Preparative isolation of aquatic humic substances. Environ. Sci. Technol. 15, 463-466.

Visser S. A. (1983) Application of Van Krevelen's graphicalstatistical method for the study of aquatic humic material. Environ. Sci. Technol. 7, 412-417.

Wang L., Chin Y.-P. and Traina S. J. (1997) Adsorption of (poly)maleic acid and an aquatic fulvic acid by goethite. Geochim. Cosmochim. Acta 61, 5313-5324.

Watt B. E., Hayes T. M., Hayes M. H. B., Price R. T., Malcolm R. L. and Jakeman P. (1996) Sugars and amino acids in humic substances isolated from British and Irish waters. Water Res. 30, $1502-1516$.

Wolf M., Buckau G. and Chanel V. (2005) Asymmetrical flow fieldflow fractionation of humic substances: comparison of polyacrylic acids and polystyrene sulfonates as molar mass standards. In Humic Substances: Molecular Details and Applications in Land and Water Conservation (eds. E. A. Ghabbour and G. Davies). Taylor and Francis, New York, pp. 23-33.

Associate editor: Donald L. Sparks 